F. Reprod. Fertil. (1960) I, I57-1 68.

\title{
CERTAIN CHARACTERISTICS OF CERVICAL MUCUS IN RELATION TO THE MENSTRUAL CYCLE
}

\author{
CLARE HARVEY, ROSEMARY A. LINN AND \\ MARGARET HADLEY JAGKSON
}

Department of Zoology, University of Exeter and Infertility Clinic, Royal Devon and Exeter Hospital, Exeter

(Received $9^{\text {th }}$ November I959)

\begin{abstract}
Summary. The consistency index of cervical mucus has been studied throughout the menstrual cycle in a group of 125 women. An attempt has been made to correlate consistency with other cyclical changes in mucus such as recoil, palm leaf reaction and tests for glucose content.

The limits of consistency within which spermatozoa will move freely in mucus have been established from post-coital samples and invasion tests in vitro.

The characteristics of twenty-four mucus samples obtained on the day when conception is known to have taken place are discussed.
\end{abstract}

\section{INTRODUCTION}

This investigation was largely inspired by the work of Scott Blair \& Glover at the National Institute for Research in Dairying on the rheology of bovine cervical mucus and by their joint work with Clift on human cervical secretion.

Since January I958, the consistency of samples of cervical mucus collected on almost every day of the cycle from women in the childbearing years attending an infertility clinic has been studied with a modification of the consistometer designed by Scott Blair (Pl. I, Fig. I) mainly for the early diagnosis of pregnancy in cows. A description of the apparatus, the method of interpreting the readings and a discussion of the rheological properties of cervical mucus will be found in various papers by that author and others (Scott Blair \& Glover, I955, I956, I957a, b; Clift, Glover \& Scott Blair, I950).

Briefly it may be stated that the constant $\mathrm{Pt}^{\frac{1}{2}}$ (or index of consistency) is estimated as follows: A thread of mucus is drawn into a capillary tube of standard bore, and then forced out under a suitable pressure. The time taken by the end of the mucus thread to travel $\mathrm{r} \mathrm{cm}$ is noted, and the product of the pressure exerted in $\mathrm{lb} / \mathrm{sq}$. in. and the square root of the time in seconds is approximately constant for any given sample of mucus; the product is called the index of consistency or $\mathrm{Pt}^{\frac{1}{2}}$. In this paper, where consistency is expressed as a number, it is calculated in this way.

An attempt has been made to correlate the consistency index with certain other characteristics of human cervical mucus, namely recoil, palm leaf 
reaction (as described by Papanicalaou, 1946; Zondek, 1954, 1956; and others) and penetrability to spermatozoa. A high proportion of the patients are keeping basal temperature charts and endometrial biopsies have been taken in many of the cycles. Recently, the amount of glucose present in the cervical mucosa (Birnberg, Kurzrok \& Laufer, 1958; Doyle, 1958) at the time of collecting samples has been tested for, with two of the test papers marketed for the purpose of detecting glucose in urine (namely 'Tes-Tape' made by Eli Lilly \& Co and 'Clinistix' made by Ames Company).

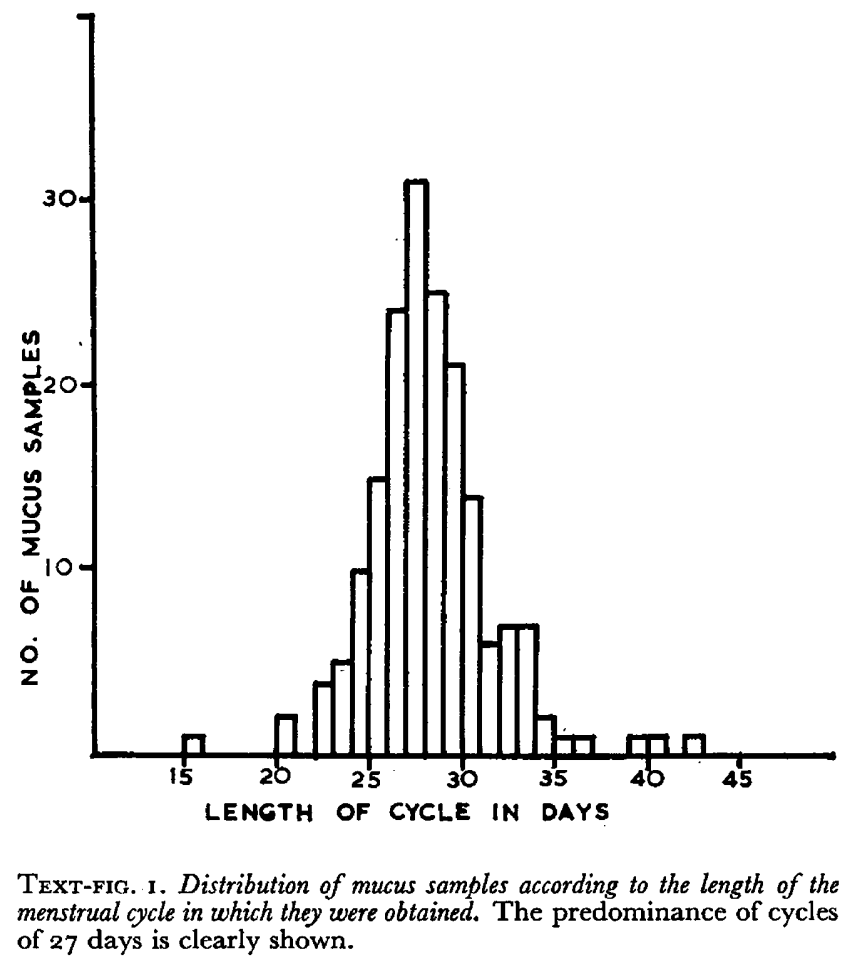

The graphs and histograms which appear in this paper are compiled from the data obtained from I 79 samples of mucus collected from I 25 women who were known to be menstruating and ovulating more or less regularly and who were not receiving hormone treatment at the time the mucus was collected. The distribution of cycle lengths in which the mucus samples under consideration were collected is shown in Text-fig. I. It will be seen that cycles of 26 , 27 and 28 days predominate.

\section{OBSERVATIONS}

CONSISTENCY

In order to minimize the effect of variations in cycle length as far as possible, the day in the cycle has been calculated with reference to the subsequent menstrual period. Text-fig. 2 shows a graph of the mean value of the consistency 


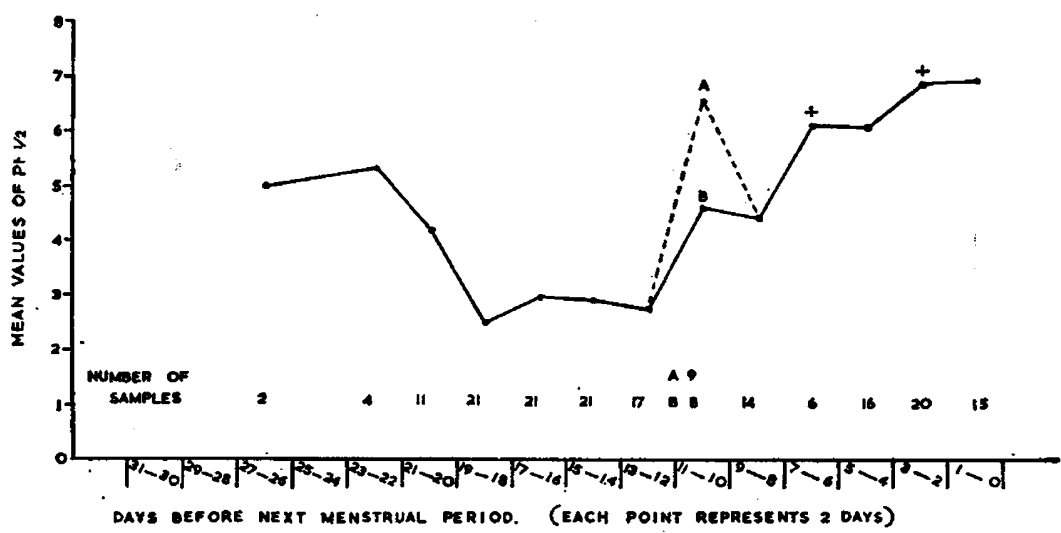

Text-pig. 2. Mean values of consistency $\left(\mathrm{Pt}^{\mathbf{3}}\right)$ at different times in the cycle. The mean value is at a minimum between the I 2 th and 19 th day before menstruation. Point $A$ includes one sample of mucus of exceptionally high consistency; if this sample is excluded, the mean for these two days is at B. On each of the days marked '+' on the chart, there was, in addition, one sample of mucus too tenacious to be assessed by the consistometer.

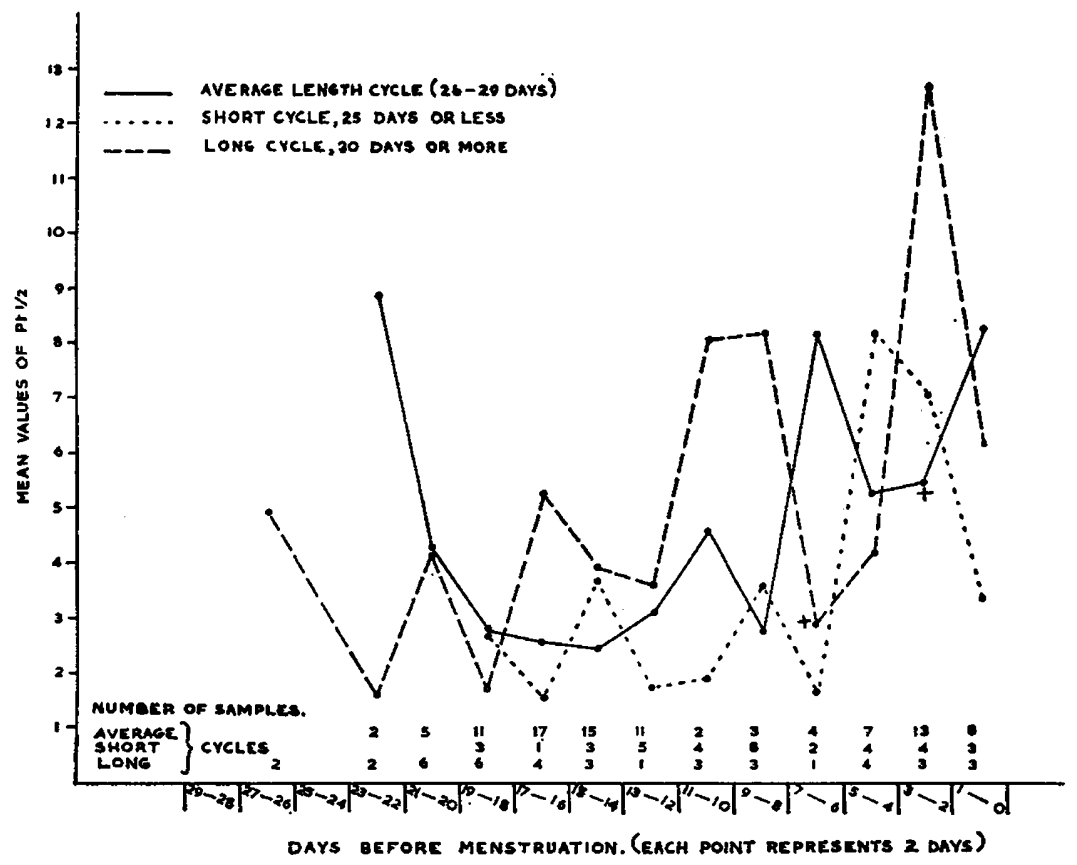

TEXT-FIG. 3. Comparison of mean values of $\mathrm{Pt}^{\frac{1}{2}}$ at different times in the cycle, in cycles of long, short and average length. This is the same data as that shown in Text-fig. 2; the exceptional samples are shown as before. Note that the period during which the consistency is at a minimum is no shorter than when all the samples are taken together. 
indices $\left(P t^{\frac{1}{2}}\right)$ of the mucus samples plotted for each 2 days before the next menstrual period (NMP). Mucus samples obtained on each 2 days of the cycle have been grouped together, i.e. o (day loss started) and I day before menstruation, 2 and 3 days before, and so on. It will be seen that the mean values for $\mathrm{Pt}^{\frac{1}{2}}$ are at their lowest and the mucus most fluid for 8 days (i.e. on the 12 th to I 9 th days before menstruation occurs). This, of course, is merely demonstrating an already well-recognized phenomenon.

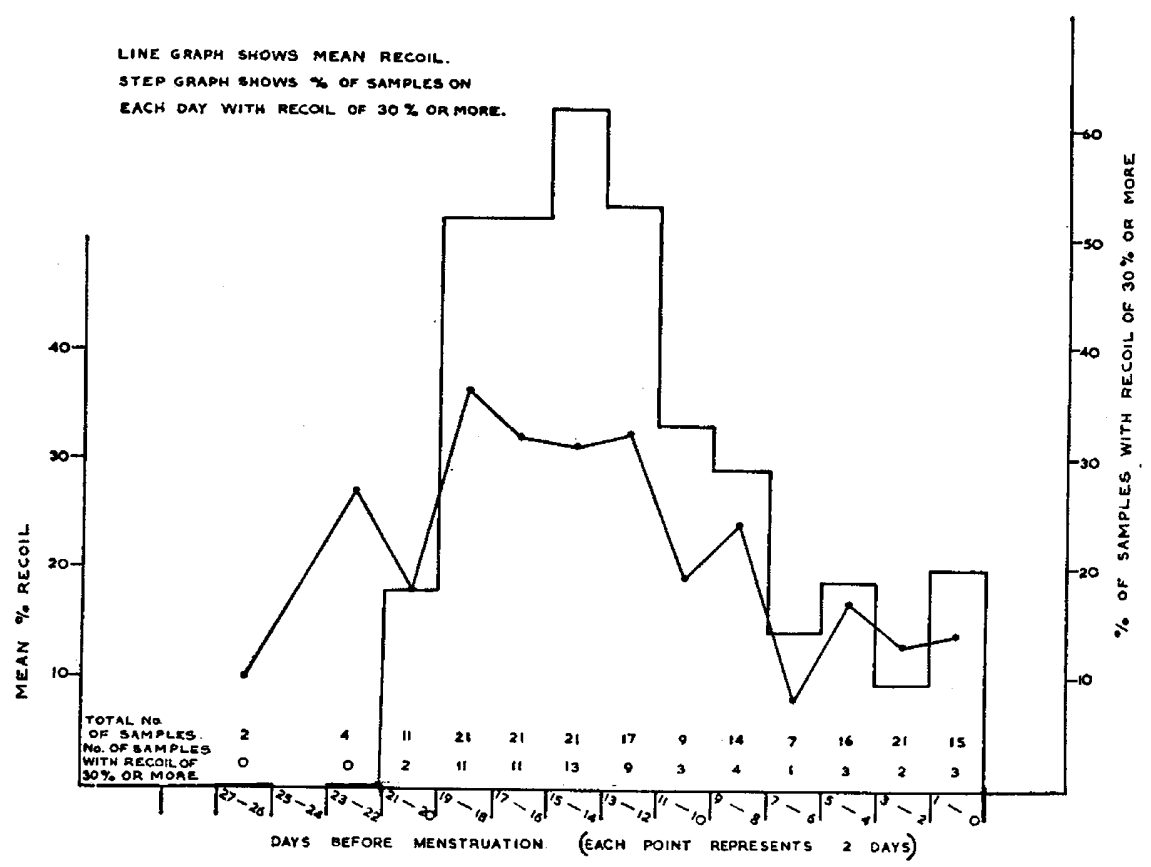

TExT-FIG. 4. Recoil at different times in the cycle. Recoil, whether considered as the mean value or as the proportion of samples with a recoil of $30 \%$ or more, is at a maximum during the same part of the cycle as that in which the mean consistency is at a minimum. The apparent peak on Days 14 to 15 does not differ significantly from the adjoining groups.

In Text-fig. 3 , the cycles have been sorted into short ( 25 days or less), average ( 26 to 29 days) and long ( 30 days and over) and the mean $\mathrm{Pt}^{\frac{1}{3}}$ values plotted separately. This has the effect of spreading the time of the lowest mean consistency to Io days or more and there is a suggestion that the mucus tends to toughen nearer to menstruation in short cycles - which may be an indication of inadequate luteal function.

\section{RECOIL}

Recoil, which is a measure of the elasticity of the mucus, has been estimated as follows: A column of mucus is drawn into the capillary tube (shown in Pl. I, Fig. I) to a point $\mathrm{X}$ and is then forced along the tube under steady pressure for a certain distance $\mathrm{X}$......Y when the pressure is suddenly released. If the mucus shows recoil it refills a part or all of the capillary between $\mathrm{X}$ and $\mathrm{Y}$ and the recoil is expressed as the percentage of the distance between $\mathrm{X}$ and $\mathrm{Y}$ refilled in $30 \mathrm{sec}$ after the pressure is removed. 
PLATE 1

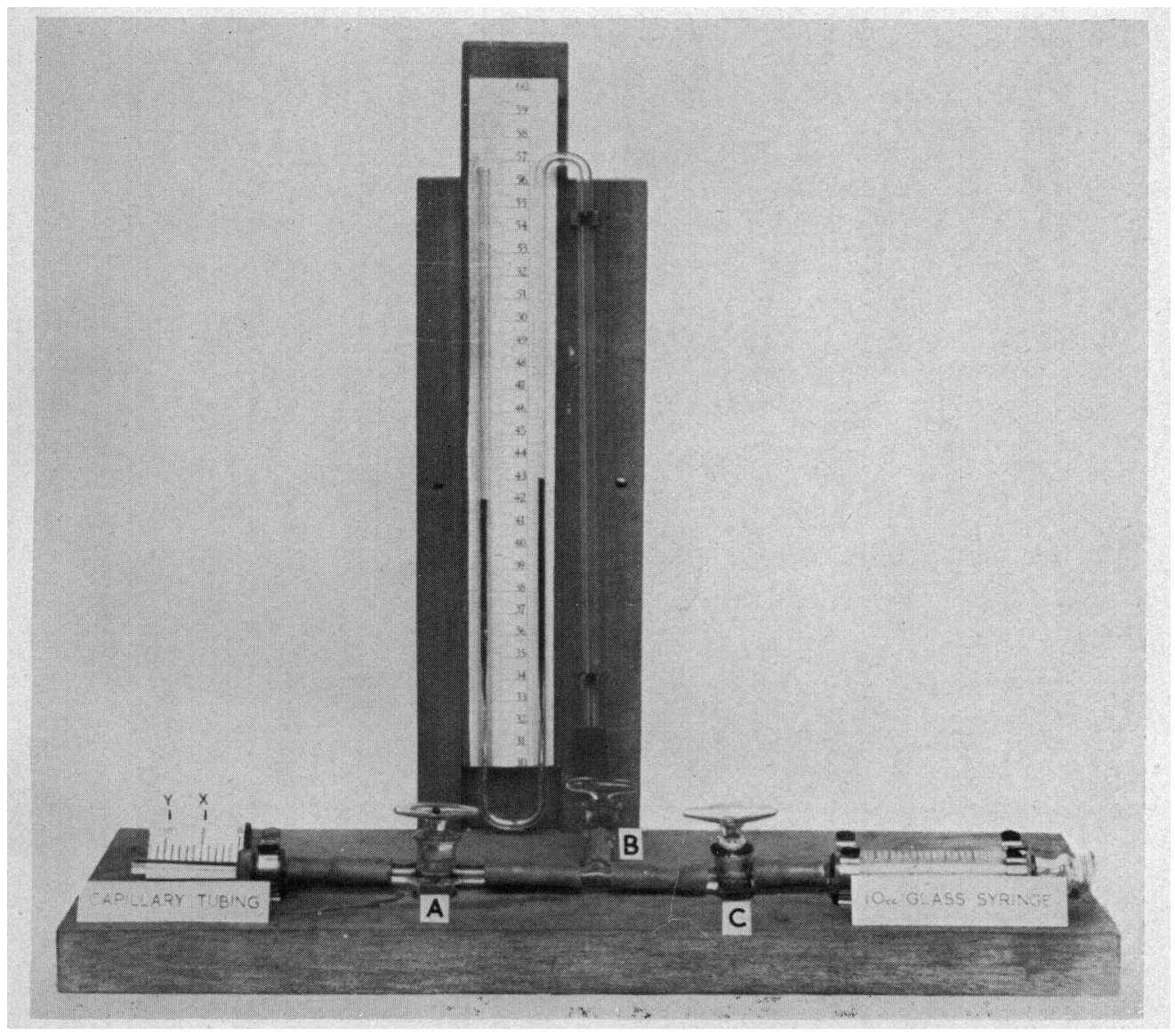

FIG. I. The instrument used for determining the consistency and recoil of cervical mucus. By means of the three-way tap A, the capillary may be connected with the rest of the instrument, or with air, and the rest of the instrument may be connected with air while closed to the capillary. Mucus is drawn into the capillary, B being closed. With A closed to the instrument, and B and $\mathrm{C}$ open, pressure is built up on the manometer. With $\mathrm{C}$ closed, B open and A connecting capillary and instrument, the time of flow is observed, and by suddenly opening $\mathrm{A}$ to air at the end of this observation, recoil can be determined.

(Facing p. I6o) 
Text-fig. 4 shows the mean value for recoil for each 2-day interval during the menstrual cycle on the linegraph; and on the stepgraph the percentage of samples in each group having a recoil of $30 \%$ or more. It will be seen that recoil is at its maximum during the same 8 to Io days when consistency is at a minimum. Indeed, there is a close inverse correlation between the value for recoil and the consistency index throughout the cycle (see Text-fig. 5).

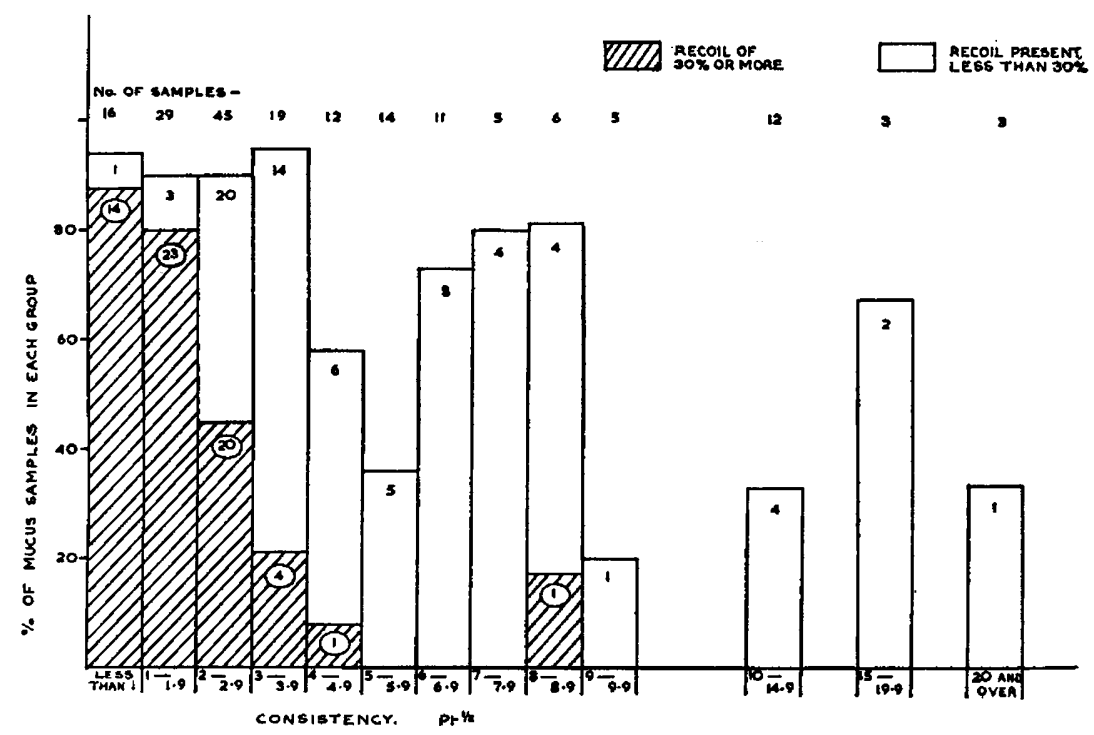

TEXT-FIG. 5. Recoil plotted against $P t^{\frac{1}{2}}$. Recoil is closely correlated with consistency, but even mucus of very high consistency may show some recoil. The figures inset in the columns give the number of samples represented in that part of the histogram.

\section{PALM LEAF REACTION (PLR)}

Where the sample of mucus was adequate, part of it was dried on a slide and examined later for PLR. Text-fig. 6 shows the proportion of samples in which a positive palm leaf reaction developed on drying.

Text-fig. 7 shows the relationship between PLR and consistency. In this series, a positive PLR has not occurred in mucus with a consistency above 6.9 but below this point there is no significant difference in the proportion of samples in each consistency group showing a positive reaction. It will be noticed that there are only eight patients in whom the PLR was positive in mucus collected within 9 days of the next period (i.e. in the immediately premenstrual phase). A negative PLR is expected then and it is of interest to scrutinize these patients and the particular cycle in which this unexpected result was obtained. Four of these women invariably had short cycles ( 26 days or less); in two, the cycles were irregular; two had reasonably regular cycles of 27 to 30 days. Basal temperature charts were being kept by six of the patients in the cycles when these particular samples of mucus were collected; two showed a well-sustained rise (these belonged to the women with normal cycles and were of 28 and 30 days' duration); in four, there was an uncertain staircase rise or no rise at all (cycle 


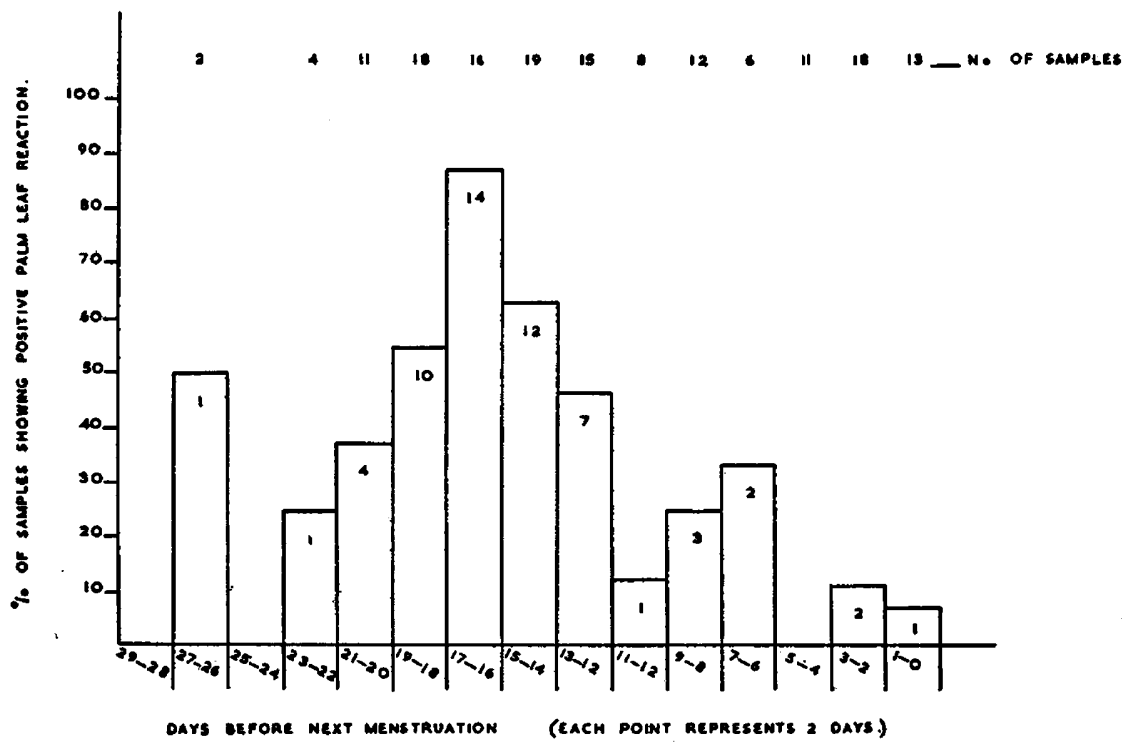

Text-Fig. 6. Distribution of positive PLR at different times in the cycle. The proportion of samples showing a positive PLR is significantly higher during the period 12 to 19 days before menstruation than during the rest of the cycle, and the excess of samples with a positive reaction on Days 16 and 17 may be significant $(P<0.05>0.01)$. Figures inset in the columns give the number of samples represented in that part of the histogram.

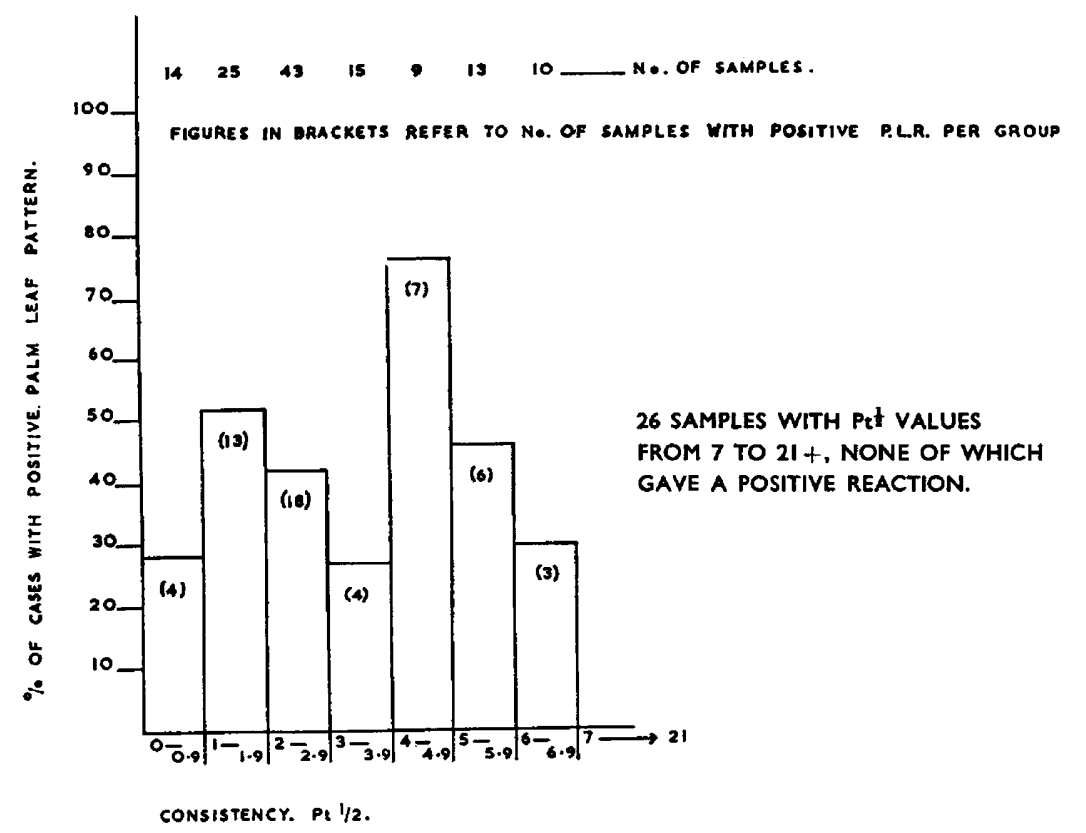

Text-pig. 7. Percentage of cases with positive PLR in each group of $P t^{\frac{1}{2}}$ values. Although no mucus with a consistency greater than 7 has given a positive PLR, the proportion of positives in each consistency group below 7 shows no correlation with consistency. 
lengths in these were $22,24,24,25$ days). Thus, in only two of these eight cases could one legitimately expect a completely negative PLR.

\section{BEHAVIOUR OF SPERMATOZOA IN RELATION TO MUGUS QUALITY}

\section{Post-coital Tests}

The relationship between consistency and the activity of spermatozoa in the mucus was studied in samples of mucus obtained within $40 \mathrm{hr}$ or less of coitus. The husbands of the patients included in the series had very varying grades of

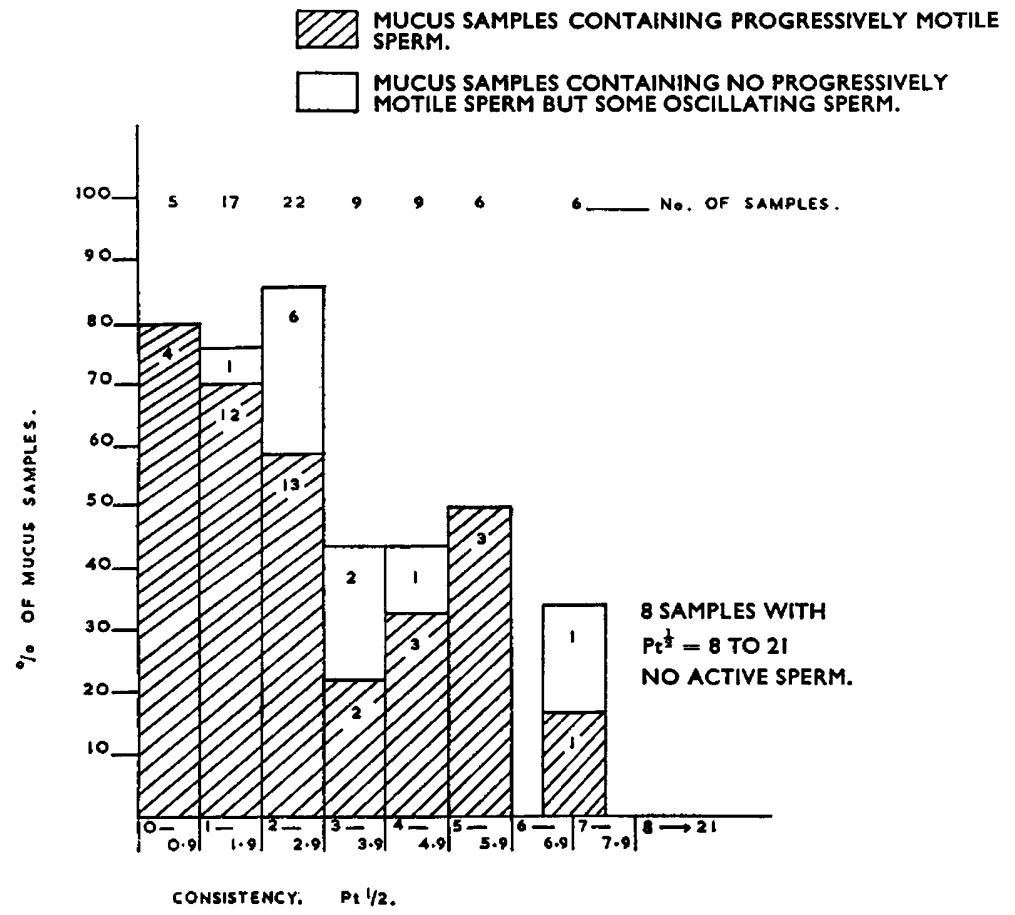

TExT-FIG. 8. Relation of $P t^{\frac{1}{2}}$ to sperm movement. All samples included contained spermatozoa, either motile or immotile, and were obtained not more than $40 \mathrm{hr}$, and usually between 16 and $20 \mathrm{hr}$, after coitus. Only two samples with a consistency of over 7 contained moving spermatozoa, and in only one of these were the spermatozoa progressing. The proportion of samples with progressing spermatozoa in the group with consistency 3 to 6.9 is significantly lower than in those with consistency below $3(P<0.02>0.01)$. Figures inset in the columns give the number of samples represented in that part of the histogram.

fertility, but none was azoospermic. In order to standardize the test, a maximum of ten high-power fields was examined in each case. In eighty-three samples of mucus from sixty-five women, spermatozoa were found in some or all of the ten fields and these samples were grouped as follows:

A. At least one spermatozoon in ten fields progressing.

B. No spermatozoa progressing but at least one showing some activity.

C. Spermatozoa present but none active in ten fields. 


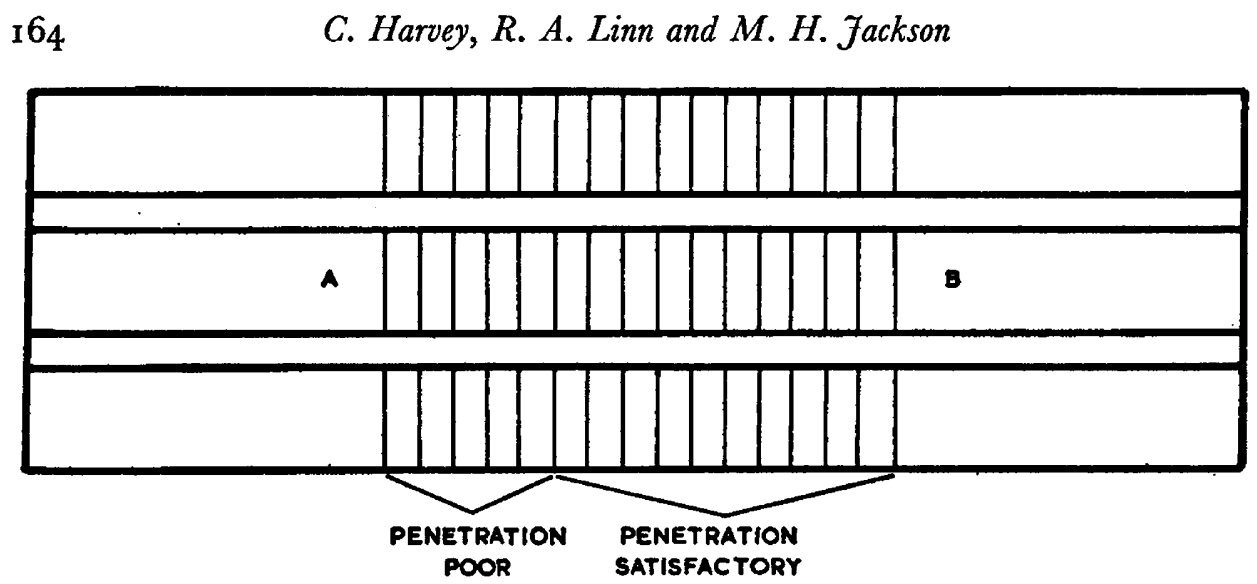

Test-Fig. 9. Illustration of cervical mucus slide. The etched lines are $2 \mathrm{~mm}$ apart. (Further details given in the legend to Text-fig. Io.)

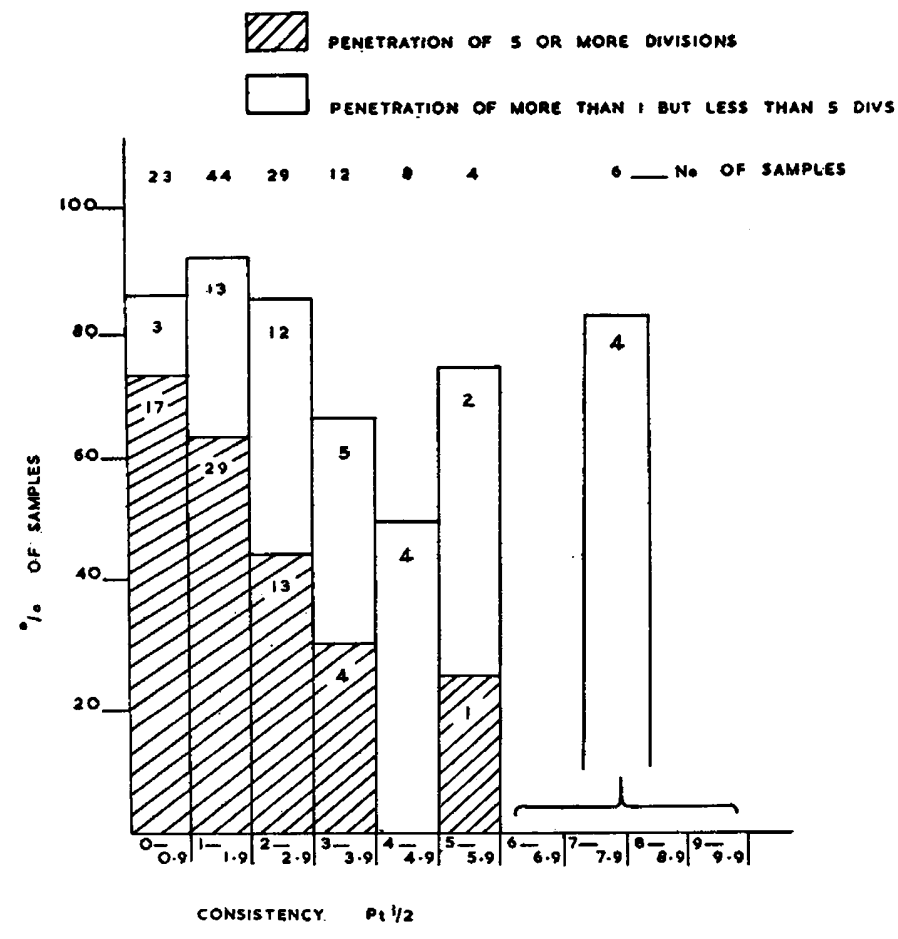

Text-fig. 10. Penetration of mucus by spermatozoa in vitro. When the quality of the spermatozoa is known to be good, failure to penetrate a strip of mucus in vitro for more than five divisions may be assumed to indicate arrest of progressive movement shortly after the spermatozoa have entered the mucus. Only one sample showed progressive spermatozoa beyond the first centimetre when the mucus consistency was above 4 , and none when the consistency was above 6 . Figures inset in the columns give the number of samples represented in that part of the histogram. 
Text-fig. 8 shows the relationship between consistency and sperm movement. In only one case were progressing spermatozoa found in mucus with a consistency index of more than 5.9 (in this case the $\mathrm{Pt}^{\frac{1}{2}}$ was 7 ). The proportion of samples found to contain progressing spermatozoa is significantly higher in mucus with a consistency index of less than 3 than in samples with higher consistencies.

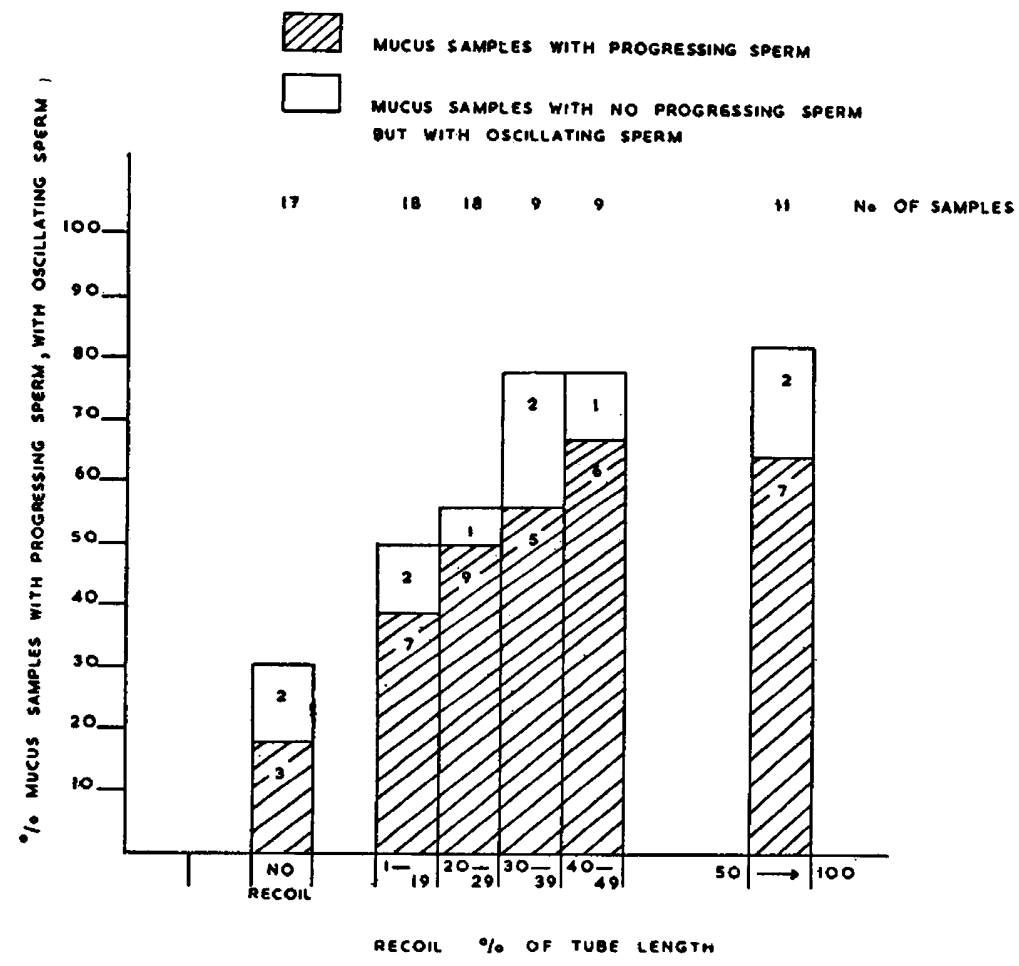

TEXT-FIG. I I. Relation of sperm activity to recoil. There is very little correlation between recoil and sperm movement, except that in the absence of recoil active spermatozoa are absent from the majority of samples. The apparent rise in the proportion of samples containing active spermatozoa with increase in recoil is not significant. Figures inset in the columns give the number of samples represented in that part of the histogram.

\section{Invasion Tests}

In a different series of cases, in which cervical mucus was collected mainly in mid-cycle, invasion tests were done with fertile semen in vitro using the slide devised by Clare Harvey (Harvey \& Jackson, 1948) (Text-fig. 9). Three centimetres of this slide is marked with etched lines $2 \mathrm{~mm}$ apart. Mucus is spread between $\mathrm{A}$ and $\mathrm{B}$ on the central portion of the slide and a drop of semen is placed at A. Penetration is regarded as 'satisfactory' if, after I-hr incubation, progressively motile spermatozoa are found beyond the first centimetre of the mucus film (Harvey, 1954). The results of this series of invasion tests have been correlated with the consistency of the mucus and it will be seen in Text-fig. Io that satisfactory invasion only occurs when $\mathrm{Pt}^{\frac{1}{2}}$ is less than 6 .

Text-fig. I I shows the relationship between sperm movement and recoil. Surprisingly, in view of the close correlation between recoil and consistency, there is very 
little correlation between recoil and sperm activity, only the lowest recoil groups showing a significant departure from random distribution. This suggests that mucus elasticity is not concerned in the mechanism of sperm progression through the mucus and that consistency is the limiting factor.

In view of these findings on sperm movement the distribution throughout the cycle of mucus samples with a consistency index of less than 6 (i.e. those samples in which spermatozoa might be expected to progress if present) was determined and the results are shown in Text-fig. I2. Practically all samples collected between the I2th and I 9 th day before the next menstrual period are of this quality and although the proportion falls off earlier and later in the cycle, there is no time when less than $40 \%$ of the samples obtained would permit sperm progression.

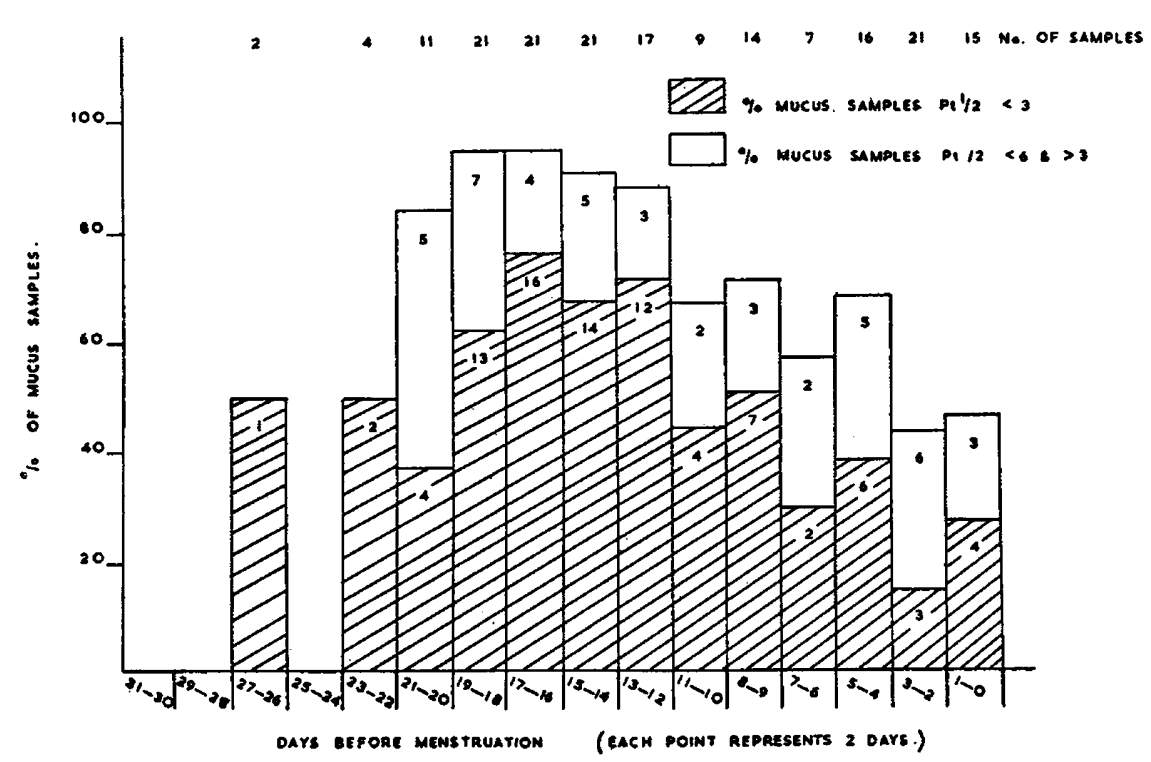

TEXT-FIG. 12. The occurrence of mucus samples with a value for $P t^{\frac{1}{2}}$ less than 6.0 at different times before the next menstruation, in 2-day groups. The columns represent the distribution throughout the menstrual cycle of samples of cervical mucus the consistency of which would permit spermatozoa to invade and progress. Compare with Text-figs. 8 and ro. Figures inset in the columns give the number of samples represented in that part of the histogram.

It has been suggested that conception could be prevented by inducing at mid-cycle, by means of hormone treatment, a mucus of such consistency that spermatozoa could not pass through it from the vagina to the uterine cavity. A consideration of the results presented here shows that to obtain such toughening the mucus would need to have a higher consistency than the maximum reached by many women at any time in a normal cycle.

The mucus characteristics studied and discussed above all show the same trends but there is no sharp change to indicate precisely where ovulation takes place; the PLR shows a peak 16 to I 7 days and recoil I $_{4}$ to I 5 days before the next period while the consistency index $\left(\mathrm{Pt}^{\frac{1}{2}}\right)$ is at its lowest between days $\mathrm{I} 2$ and 19. 
We have been quite unable to get any indication of a peak in the amount of reducing substance in the cervical canal at any point in the cycle; the readings in more than fifty tests with two types of testing paper have been completely erratic. The paper was passed through the exposed external os well up into the cervical canal and left there for I min or more. 'Clinistix' turned blue on almost every occasion; 'Tes-Tape' showed no change at all or patches of green of various shades at any point in the cycle: contrary to expectations some of the deepest greens were obtained in the premenstrual phase. According to tests carried out with serial dilutions of glucose, 'Tes-Tape' will detect the sugar in a concentration of about $I$ in 4000 whereas 'Clinistix' does so at I in 8000 . It seems possible that a tape that would detect glucose at about $\mathrm{I}$ in 6000 might be worth trying.

DATA AGGUMULATED IN GASES OF A.I. ON DAYS WHEN GONCEPTION IS KNOWN TO HAVE RESULTED

We thought it would be of interest to collect and correlate the data accumulated since January i $95^{8}$ on cervical mucus collected from patients on days when conception was known to have occurred. There are twenty-four such cases and in every case we have the following data: Last menstrual period and, therefore, cycle day on which conception occurred; basal-temperature chart; naked eye description of mucus sample; character of thread; PLR. In seventeen, we have in addition readings for consistency $\left(\mathrm{Pt}^{\frac{1}{2}}\right)$ and recoil, and a penetration test in vitro. In six, 'Tes-Tape' readings were made. We have not included the vaginal smear in this investigation, not because we do not think it a useful indicator, but because it did not fit in with the work as planned.

Day in Cycle. The most popular days were 12 and 13 : nine conceived on Day I3; seven on Day I2; three on Day II; two on Day I4; one each on Days I5 and 16 and one on Day 36 (a woman with extremely irregular cycles).

Basal Temperature. A carefully kept basal-temperature chart gives valuable information, provided there are several cycles to look at so that the day when the rise is most likely to occur can be calculated with some certainty. In these twenty-four women, conception occurred eleven times on the day before, four times 2 days before and five times 3 days before the rise started; one occurred I day after and one 2 days after the rise started. In one case the chart was too badly kept to be of any value.

Appearance of Mucus and Thread. In twenty-one cases, the mucus was described as 'runny' or 'fairly runny' with good thread, in two as 'tenacious' or 'slightly tenacious' and in one as 'markedly tenacious' with no thread. This patient has been examined on many different days in the cycle and has never produced an ovulatory mucus with a good thread. Nevertheless she has conceived twice as a result of A.I.

Palm Leaf Reaction. This was positive in all cases but the excellence of the fern pattern varied considerably. Even the markedly tenacious mucus mentioned above showed some attempt at fern formation.

Penetration Test. This was carried out on the mucus samples in nineteen cases; 
in ten the spermatozoa penetrated rapidly to the end of mucus, in eight cases there was some penetration but not complete. In the case with extremely tenacious mucus mentioned above, there was no penetration.

Consistency Index and Recoil. All but two of the seventeen mucus samples examined had values for $\mathrm{Pt}^{\frac{1}{2}}$ under 3 , and in all but five recoil was $30 \%$ or over. One sample gave a $\mathrm{Pt}^{\frac{2}{2}}$ of 3.88 , and the markedly tenacious mucus referred to above had a $\mathrm{Pt}^{\frac{1}{2}}$ of 10.83 , with no recoil.

'Tes-Tape' Readings. The colour changes in the six cases where this test was done ranged from 'no change' through 'pale green tinge' to 'bright green patch'.

Thus, of these nine characteristics the most valuable and practical aids to the clinician in the consulting-room or clinic for pinpointing ovulation seem still to be the basal temperature chart followed closely by the appearance of the mucus and character of the thread; cycle Days 12 and 13 stand out as the best bet on which to carry out insemination or to advise a couple to have coitus.

Among the babies already born there are eleven boys and five girls; insemination in all these cases was carried out before the rise.

\section{ACKNOWLEDGMENTS}

Clare Harvey is in receipt of a grant from the South West Regional Hospital Board. The M.R.C. provided a grant for Rosemary Linn to assist in this work.

\section{REFERENCES}

Clift, A., Glover, F. A. \& Scott Blair, G. W. (1950) The rheology of human cervical secretions; effects of menstrual cycle and pregnancy. Lancet, ii, i I 54 .

Birnberg, C. H., Kurzrok, R. \& Laufer, A. (1958) Simple test for determining ovulation time. $\mathcal{F}$. Amer. med. Ass. 166, i 174 .

Doyl., J. B. (1958) Cervical tampon. Synchronous test for ovulation. 7. Amer. med. Ass. 167, 1464.

HARVEY, C. (1954) An experimental study of the penetration of human cervical mucus by spermatozoa in vitro. F. Obstet. Gynaec., Brit. Emp. 41, 480.

Harvey, C. \& JACKson, M. H. (1948) Penetration of cervical mucus by spermatozoa. Lancet, ii, 723.

Papanicalaou, G. N. (1946) General survey of vaginal smear and its use in research and diagnosis. Amer. F. Obstet. Gynaec. $51,316$.

ScotT BlaiR, G. W. \& Glover, F. A. (1955) Early pregnancy test from studies of bovine cervical mucus. Brit. vet $\mathcal{F}$. III, 3 .

Scott Blair, G. W. \& Glover, F. A. (1956) The measurement of consistency of some biological fluids using a new microconsistometer. Lab. Pract. 5, I25.

Scott Blair, G. W. \& Glover, F. A. (I957a) More early pregnancy tests from studies of bovine cervical mucus. Brit. vet. $\mathcal{F}$. $113,4^{1} 7$.

Scott Blair, G. W. \& Glover, F. A. (1957b) Crystallization patterns of sodium chloride in bovine cervical mucus as related to consistency. Nature, I79, 420 .

ZONDEK, B. (1954) Some problems related to ovarian function and to pregnancy. Recent Progr. Horm. Res. I0, 395 .

ZonDEK, B. (I956) Functional significance of the cervical mucus. Proc. IInd World Congr. Fertility $\mathbb{E}$ Sterility, Naples, $\mathbf{1}, 463$. 